\title{
An Estimation of the Incidence of Thyroiditis Among Girls in Primary Care in Spain
}

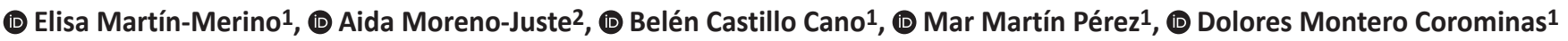 \\ 1Spanish Agency for Medicines and Medical Devices (AEMPS), Department of Medicines for Human Use, Pharmacoepidemiology and \\ Pharmacovigilance Unit, Madrid, Spain \\ 2Servicio Aragonés de Salud (SALUD); EpiChron Research Group, Aragon Health Sciences Institute (IACS), IIS Aragón; Red de Investigación en \\ Servicios de Salud en Enfermedades Crónicas (REDISSEC), Zaragoza, Spain
}

\section{What is already known on this topic?}

Current estimates of the incidence of thyroid dysfunction derive from adults and are limited for children and adolescents. The majority of thyroiditis cases occurs in females; an early diagnosis is relevant to prevent complications, mainly in childhood growth and maturation and metabolism of the nervous system.

\section{What this study adds?}

Among girls aged 9-18 years in Spain, the incidence of thyroiditis was estimated at 20.83-32.12/100,000 person years, and a temporal increase was also identified. Among thyroiditis cases, $\geq 50 \%$ were autoimmune, $43 \%$ not specified, and $3 \%$ referred to other types. Delayed diagnosis was suggested in $10 \%$ of the cases, which is important due to possible clinically significant consequences.

\section{Abstract}

Objective: As for other auto-immune processes, thyroiditis is monitored after vaccinations. The aim was to estimate the baseline incidence of thyroiditis among girls, before investigating papillomavirus vaccination as a potential risk factor.

Methods: Observational cohort study including girls aged 9-18 years and registered between 2002-2016 in the Spanish Primary Care Database for Pharmacoepidemiological Research. Girls were followed until a thyroiditis occurred, 19 years of age, left the cohort, died, or the study ended. Anonymized records were reviewed for diagnosis confirmation (endocrine discharge letter and/or free-text comments) in a random sample. Incidence rate (IR) per $10^{5}$ person years $\left(/ 10^{5}\right.$ py) was estimated.

Results: The cohort numbered 480,169 girls, of whom 641 had a record of thyroiditis: 346 autoimmune thyroiditis; 17 thyroiditis of other types; and 278 unspecified. Incidence of recorded thyroiditis increased with age, from 23.96 at age 9 years to 47.91 at age 14 years, and stabilized around 31.06-34.43 among girls aged 15-18 years. Of the 98 records reviewed, 60.2\% were 'confirmed' cases, $32.7 \%$ 'possible' and $7.1 \%$ were discarded. After correction for discarded cases, IR $=20.83$ 'confirmed' cases, increasing to $32.12 / 10^{5}$ py when 'confirmed' plus 'possible' cases were included. Between 2002-2005, incidences were lower (16.28 and 20.93 cases/10 5 py) than in the period 2007-2016 (21.17 and 33.78 cases/10 py) for 'confirmed' and 'confirmed' plus 'possible', respectively.

Conclusion: Two-thirds of the recorded thyroiditis included confirmatory evidence. The incidence of thyroiditis among girls increased with age and in the later period, and remained stable among girls aged 15-18 years.

Keywords: Thyroiditis, women, incidence, precision of recording, International Classification of Primary Care codes, ICD-9 codes, primary care electronic records, paediatric thyroid disease

Address for Correspondence: Elisa Martín-Merino MD, Spanish Agency for Medicines and Medical Devices (AEMPS), Department of Medicines for Human Use, Pharmacoepidemiology and Pharmacovigilance Unit, Madrid, Spain

Phone: (+ 34) 918225264 E-mail: emartinm@aemps.es ORCID: orcid.org/0000-0002-3576-8605

${ }^{\circ}$ Copyright 2021 by Turkish Pediatric Endocrinology and Diabetes Society

The Journal of Clinical Research in Pediatric Endocrinology published by Galenos Publishing House.
Conflict of interest: None declared Received: 23.09 .2020 Accepted: 24.11 .2020 


\section{Introduction}

Thyroid dysfunction is one of the most common endocrine disorders in clinical practice (1). The incidence is influenced by a number of factors, with age, sex, geographic factors or ethnicity known to be important (2).

Thyroid dysfunction is associated with morbidity and deleterious consequences in terms of coronary artery disease and cardiovascular mortality. In order to prevent complications, routine screening programs that facilitate appropriate timely treatment are recommended (3). Therefore, determining the epidemiology and distribution of thyroid dysfunction in the European population, as well as trends in population subgroups, is relevant for designing tailored public health policies and programs (3). Current estimates of the prevalence of thyroid dysfunction are largely derived from data in white middle-aged populations (1) and limited data are available in children. Autoimmune thyroiditis (AIT) is the most common thyroid disorder in the paediatric population, being either goitrous (Hashimoto's thyroiditis) or non goitrous (atrophic thyroiditis, also known as primary myxedema). In this population, the most common period at presentation is adolescence, but the disease may occur at any time, even in children under one year of age, and is more common in girls (4).

Thyroid hormones play an important role in childhood growth and are involved in the maturation and metabolism of certain organs, such as the skeleton and brain, influencing the process of myelination of the nervous system. As a consequence, some of the differences in children and adults presenting with Hashimoto thyroiditis occur because the hypothyroidism affects developing systems rather than matured systems and in children may result in short stature, decline in school performance, and retardation of development (5).

We are currently studying the possible role of human papilloma virus vaccination (HPVv) in the development of immune mediated disorders, including some forms of thyroiditis. In order to facilitate this study, it was planned to estimate the recording of thyroiditis among girls at ages when HPVv is given in Spain in order to confirm the precision (internal validation) and sensitivity (external validation) of the data in the Spanish Primary Care Database For Pharmacoepidemiological Research (BIFAP), as well as providing incidence rates (IR) of thyroiditis in this population.

\section{Methods}

\section{Source of Data}

In the current study, BIFAP was used as the data source (6). BIFAP is a longitudinal population-based database of anonymised electronic primary care records from 881 paediatricians and 5871 physicians of the Spanish public National Health System (S.N.S.). In Spain, around 98.9\% of the population is registered with a local primary care paediatrician or physician (PCPs) of the S.N.S (7).

BIFAP contains information for $66 \%$ of the girls aged 1019 years as registered in the Spanish census (7) from 7 out of 19 regions. Available data include patient age, sex, clinical events which are recorded using the International Classification of Primary Care (ICPC) and the International Classification of Diseases $9^{\text {th }}$ revision (ICD-9) $(8,9)$, anonymised PCPs free text notes, specialist referrals and discharge letters, prescriptions issued in primary care and their dispensation by pharmacies, vaccinations, laboratory test results and life-style factors, including body mass index, smoking status, and alcohol consumption.

BIFAP is fully funded by the Spanish Agency on Medicines and Medical Devices (10), is overseen by the Department of Health, and is maintained with the collaboration of the participant regions.

The current study is part of a broader project intended to study the use and safety of the HPVv. This study was funded by Instituto de Salud Carlos 3 through the project 'PI1 7/02300' (Co-funded by European Regional Development Fund) and the study protocol was approved by the Scientific Committee of BIFAP (Reference BIFAP_01_2016).

\section{Study Design and Population}

In this observational cohort study, based on information collected retrospectively, the population was composed of girls aged 9-18 years registered in BIFAP from 2002 (first year for standard quality in data collection in the database) to 2016 (last year of data available at the moment the study was performed), with PCP medical records for at least one year and without a previous diagnosis of thyroiditis. The start date of follow-up was defined as the last date of fulfilling all inclusion criteria.

\section{Thyroiditis Automatic Identification}

Girls were followed from the start date until a recorded ICPC/ICD-9 code for thyroiditis diagnosis (listed in Annex 1) was identified, they reached 19 years of age, left the cohort, died, or the study ended (31 December 2016).

According to the description of the thyroiditis codes, cases were categorized as autoimmune (including Hashimoto, Graves-Basedow or Graves' disease), unspecified, and other types which included acute, sub-acute, chronic, silent or viral (Annex 1).

In order to assess a potential temporal change in the incidence of thyroiditis over the period of the study, the 
analysis was replicated in two periods 2002-2005 (previous to the marketing approval of the HPVv by regulatory agencies) and 2007-2016 (once HPV vaccination was scheduled for girls and female adolescents). The HPVv were approved for marketing in Spain during the last months of 2006. Thus the year 2006 was excluded from this time trend analysis, as interrupted time, in order to clearly distinguish between those two periods.

\section{Review of Thyroiditis Records and Diagnosis Precision}

The anonymized clinical profiles of a random sample of girls with thyroiditis identified automatically were manually reviewed to retrieve:

- Cases with 'confirmatory' diagnosis information, such as a letter to/from a referral (mostly to an endocrinologist) or hospital, or free-text comments mentioning a clear diagnosis (as gold standard);

- Cases with information which led to rejection of the diagnosis, which included prevalent cases, confirmation of an alternative diagnosis or only reference to family history;

- Cases lacking information to confirm or disregard the diagnosis. These were considered 'possible' cases.

The sample was randomised by simply assigning a random number to each identified girl through the 'random' function in Excel program (i.e. [ = RAND ()]). Then, in order to extract the amount of profiles required to review, we just filtered those random numbers by random ranges.

In order to adjust for a delay from diagnosis to the recording or a delay in the diagnosis from the moment the first symptoms were consulted, the date of first prescriptions of (anti-)thyroid hormones, propranolol (used as a symptomatic treatment to control adrenergic symptoms) (11) as well as the ICPC/ICD coding linked electronically to thyroiditis by the PCP were extracted. Among them, the earliest date was used as thyroiditis onset, for the purposes of this study.

\section{Statistical Analysis}

In order to calculate the positive predictive value (PPV), we defined as gold standard the scenario where all 'possible' cases were in fact false positives, and broad gold standard as the scenario where all 'possible' cases were true positives. Thus, PPV for the gold standard was the proportion of 'confirmed' thyroiditis cases over all patients automatically identified and PPV for the broad gold standard included also 'possible' thyroiditis cases. PPV was calculated also by type of thyroiditis, calendar period, and the presence of a thyroid peroxidase (TPO) test in the patient records.
The sensitivity of records with a detailed type of thyroiditis and TPO test to detect all cases was estimated for the gold standard, dividing the number of 'confirmed' cases in each category by the total 'confirmed' cases. Similar calculations were performed for broad gold standard including both 'confirmed' and 'possible' cases.

The so-called observed (12) IR of thyroiditis per 100,000 person-years $\left(/ 10^{5}\right.$ py) was calculated by dividing the number of recorded thyroiditis cases by the total number of person-years of follow-up in the study cohort, overall and by age group.

The expected 'confirmed' and 'possible' cases were estimated by applying PPV to the observed thyroiditis. The so-called true (12) IRs were then estimated by using the number of expected 'confirmed' or 'confirmed' plus 'possible' thyroiditis cases for both scenarios, overall and by age groups. IRs were also estimated for the two calendar periods considered, i.e. from 2002 to 2005 and from 2007 to 2016.

\section{Results}

\section{Description of Thyroiditis Records and Incidence Estimations}

In total, 480,169 girls who met the initial inclusion criteria were identified, of whom 641 had a recorded thyroiditis diagnosis, and $40.9 \%$ of them having a TPO test recorded (Figure 1). The distribution of 641 thyroiditis records by calendar year is shown in Table 1 . The type of thyroiditis was given as 'autoimmune' in 346 cases (53.98\%), unspecified in 278 cases $(43.37 \%)$ and other types in 17 cases $(2.65 \%)$ the latter category including acute $(n=15)$, viral $(n=1)$ and silent thyroiditis $(n=1)$. The IR of recorded thyroiditis was $34.59 / 10^{5}$ py, being $18.67 / 10^{5}$ py for AIT, $15.00 / 10^{5}$ py for unspecified thyroiditis and $0.92 / 10^{5}$ py for other types of thyroiditis.

The number of girls with recorded thyroiditis and the observed IRs at each age are shown in Figure 2. The IR increased with age from 23.96 (among girls aged 9 years) to 47.91 (among girls aged 14 years) per $10^{5} \mathrm{py}$, and decreased, remaining stable (between 31.90-34.43 per $10^{5}$ py), in girls aged 15-18 years.

A manual review was performed for a random sample of 98 out of the 641 identified thyroiditis records (15.3\%) and 59 of them were classified as 'confirmed' thyroiditis cases (PPV $=60.2 \%), 32.7 \%(n=32)$ as 'possible' cases and $7.1 \%$ $(\mathrm{n}=7)$ were discarded. The reason for ruling out seven cases included prevalent cases $(n=4)$, suspected thyroiditis ruled out in subsequent visits $(n=2)$ and term related only to the patient's family history of thyroiditis $(n=1)$. The PPV 


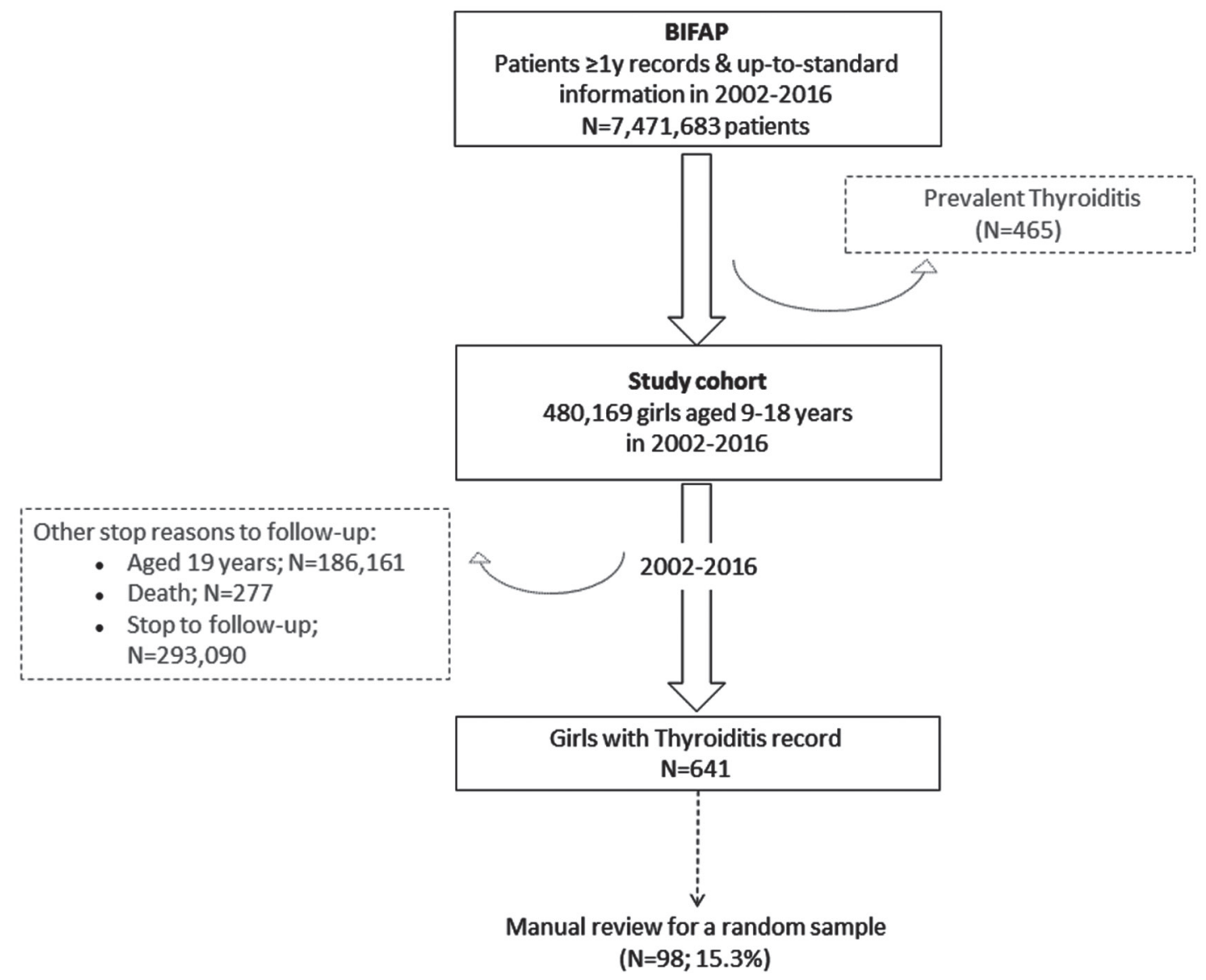

Figure 1. Study population ascertainment and follow-up until thyroiditis recording

was similar among recorded AIT (60.0\%) and thyroiditis of unspecified type (61.7\%), and slightly higher among patients with recorded TPO test results $(65.1 \%)$ than among patients without TPO test results recorded (56.4\%) (see Table 2). PPV was $92.9 \%$ for the broad gold standard, being $92.0 \%$ for AIT, and $93.6 \%$ for unspecified type.

Extrapolating these proportions to the 641 cases of thyroiditis recorded, it was estimated that 386 'confirmed', 209 'possible' and 46 discarded thyroiditis cases would occur in the study cohort if all records were manually reviewed. Thus, the true IR was 20.83 'confirmed' thyroiditis cases per $10^{5}$ py, which increased to $32.12 / 10^{5}$ py when 'possible' thyroiditis cases were also included. The IR increased with age from 9 to 14 years, and decreased thereafter, being stable for girls aged 15-18 years, as shown in Figure 2. For the period 2002-2005 the crude IR (16.28 and 20.93 per $10^{5}$ py) was lower than for the period 2007-2016 (21.17 and 33.78 per $10^{5}$ py) for 'confirmed' and 'confirmed' plus 'possible' cases, respectively.

Of the 641 thyroiditis cases recorded, 64 had a prescription $(n=57)$ and/or signs compatible with the disease $(n=49)$ registered before the diagnosis of thyroiditis was included, with a median of 591 days that could suggest a delay in thyroiditis recording. Prescriptions included levothyroxine (in 45 girls), anti-thyroid drugs (thiamazole or carbimazole; $n=13)$ and propranolol $(n=11)$. Most propranolol prescriptions had linked ICPC mentioning hyperthyroidism, bocio/thyrotoxicosis, or Graves-Basedow disease. Other beta-blockers were not prescribed. Linked signs and freetext comments to the record of thyroiditis were related to the thyroid status examination and included requested lab test (or its results) as well as signs compatible with thyroiditis.

\section{Discussion}

The current study provides valuable information on how thyroiditis is recorded among girls in primary healthcare records and on the incidence of the disease in such a population in Spain. Among the recorded thyroiditis episodes, few false positives $(7 \%)$ were found, while twothirds were 'confirmed' and a third had a thyroiditis record without additional evidence. After correcting for false positives, the IR did not change markedly compared 


\begin{tabular}{lll}
\hline $\begin{array}{l}\text { Table 1. Distribution of newly diagnosed thyroiditis cases } \\
\text { by calendar year }\end{array}$ & \\
\hline $\begin{array}{l}\text { Year of thyroiditis } \\
\text { record }\end{array}$ & $\begin{array}{l}\text { Number of } \\
\text { thyroiditis cases }\end{array}$ & Proportion (\%) \\
Total & 641 & 100.00 \\
2002 & 3 & 0.47 \\
2003 & 14 & 2.18 \\
2004 & 7 & 1.09 \\
2005 & 23 & 3.59 \\
2006 & 28 & 4.37 \\
2007 & 33 & 5.15 \\
2008 & 36 & 5.62 \\
2009 & 39 & 6.08 \\
2010 & 38 & 5.93 \\
2011 & 41 & 6.40 \\
2012 & 74 & 11.54 \\
2013 & 77 & 12.01 \\
2014 & 72 & 11.23 \\
2015 & 79 & 12.32 \\
2016 & 77 & 12.01 \\
\hline
\end{tabular}

For the estimation of the global incidence of thyroiditis between 2002 and 2016, each calendar year was included. For the estimation of the potential incidence change over the years, two periods were designated, i.e. 2002-2005 and 2007-2016, while an interrupted period, 2006 when vaccination began, was also designated

to the observed IR (from 34.59 to 32.12 cases $/ 10^{5}$ py), but decreased to 20.83 cases $/ 10^{5}$ py when only cases with confirmatory information were included (gold standard). The true incidence of thyroiditis peaked in girls aged 13-14 years, as expected, and increased around 5-13 times from the period 2002-2005 to the period 2007-2016.

A previous precision study on the recording of new-onset autoimmune conditions (including thyroiditis and others) in primary healthcare databases, also reported confirmation rates in the same range (31-40\%) (13). Gold standard information for thyroiditis diagnosis may be rather complex to be defined using secondary sources of data. For instance, the values of an hormonal test including thyrotropin (thyroid-stimulating hormone), free thyroxine (FT4), triiodothyronine (FT3) and anti-TPO antibody (anti-TPO-Ab) are commonly used for diagnosis $(11,14,15,16)$ and may be commonly recorded in the databases, as found with BIFAP. However, the criteria for the diagnosis of thyroiditis based on hormonal tests, may be different according to patients' age and sex, type of test, medical setting or region. Therefore, specific guidelines may be needed. Our data suggest a slight increase in the PPV among clinical profiles including TPO results $(65.1 \%$ with TPO vs $56.4 \%$ without TPO in gold standard; $93.03 \%$ with TPO vs $92.72 \%$ without TPO in broad gold standard) but did not add value to the global PPV
(60.2\% and $92.2 \%$, respectively). Thus, TPO test record as a 'yes/no' response is not valuable as a component for future automatic algorithms for exploring thyroiditis cases.

Regarding the date of thyroiditis recording, few patients $(10 \%)$ had previous prescriptions of anti-thyroid drugs, thyroid hormone supplementation or propranolol, or past medical comments linked electronically to thyroiditis by the PCP. These factors were recorded at a median of 1.6 years before the diagnosis, suggesting a substantial delay in the recording of thyroiditis versus diagnosis or a delay in the diagnosis compared with the initial presentation for consultation about symptoms. This delay must be taken into account when using this information for evaluating risk factors. The finding of anti-thyroid drugs or thyroid hormone supplementation provided absolute reassurance of the case, since these drugs are only used in the treatment of thyroid diseases (3).

Few papers report on the incidence of overall thyroiditis in children and adolescents, being more frequently focused on specific types of thyroiditis, such as AIT, Hashimoto or Graves' disease or related symptoms. For instance, a study performed in the UK using the information recorded in the Clinical Practice Research Datalink GOLD database (similar to BIFAP) estimated an incidence of $5.52 \mathrm{AIT} / 10^{5}$ py among 130,000 females aged 9-18 years for the period 2008-2010, increasing to 8.3 for females aged $18-25$ years (17). In that study, incidences ranged from 6.17 [95\% confidence interval $(\mathrm{CI}): 1.68-15.80 ; \mathrm{n}=4]$ to $23.18(12.98 ; 38.24$; $\mathrm{n}=15$ ) 'confirmed' cases per 100,000 female-years among females with different profiles, increasing up to 27.76 (95\% CI: $16.45-43.87 ; n=18)$ and 40.18 (95\% CI: 26.25; 58.88; $\mathrm{n}=26$ ), when 'confirmed' and 'possible' cases were included (17). Although CIs are of scarce precision, due to the small number of cases observed, the results from our study overlap with those calculations with estimates of 20.83 'confirmed' and 32.12 'confirmed' plus 'possible' $110^{5} \mathrm{py}$. The incidence of Graves' disease, which accounts for $95 \%$ of hyperthyroidism in children (18), has been estimated at $27.8 / 10^{5}$ py (95\% CI: 13.9-49.7) for females aged 10-14 years in a Hong Kong study in 1994-1998 (19), with a male to female ratio of $1: 9.7$ and lower among younger girls aged 5-9 years (i.e. $7.6 / 10^{5}$ py [95\% CI: 1.6 to 22.3]). Similarly, in the US (13) 26 new-onset cases of Graves' disease per $10^{5}$ py were found among women aged 9-26 years as well as 81 Hashimoto cases per $10^{5}$ py. Also, the incidence of thyrotoxicosis increased with age, from 0.1 (among girls aged < 5 years), 0.6-0.98 (among girls aged 5-9 years) to $3-3.4 / 10^{5}$ py (in adolescents girls aged 10-14 years) in Denmark (20), the UK and Ireland (21), observing 
a female preponderance from childhood (versus incidences found among boys: 0.1, 0.1-0.3 and 0.48-1.1, respectively).

As observed, a broad range of IRs has been reported, probably due to different methods for data collection (voluntary participation of paediatricians, the use of electronic health records or the performance of surveys), the period covered or the populations' characteristics, including geographical area, clinical setting or health system, among others.

Estimations of hyperthyroidism, hypothyroidism or childhood thyrotoxicosis occurrence, regardless of the aetiology, are more commonly found in the literature. Such incidences were below 3 per 100,000 in Sweden (22,23), increasing over the years (23). In a French study, the number of cases of treated hyperthyroidism for Graves' disease, due to Graves' disease in $95 \%$ (18), also increased with age, being estimated at 7.89 per 100,000 among girls aged 1014 years and 21.53 per 100,000 among girls aged 15-17 years (24). We found similar IR for thyroiditis of any type.

The slight increase in the crude IR found in the second period studied (2007-2016) versus the previous period (2002-2005) is in line with the reported temporal increase of hyperthyroidism or autoimmune disorders among children $(25,26,27)$. However, changes along the years in the recording habits of participating PCP (that can be related to getting used to the computer record systems or to other factors), thyroiditis diagnosis criteria, regions collaborating, the age of participants or a less precise rate due to a lower population size in the former period $(\mathrm{N}=129,835$ girls) versus the latest one $(\mathrm{N}=423,960)$ as well as other unknown factors may have also contributed to observe a difference between the two periods that might be lower or even confounded. In order to confirm any time trend, further control of the yearly incidences by confounders, is waranteed.

Complications associated with either overt or subclinical thyroid dysfunction cannot be neglected, being especially severe in patients with cardiovascular diseases, in postmenopausal women, or in women antedating pregnancy. Since the incidence in children and adolescents appears significant, early diagnosis is relevant to prevent complications associated with thyroiditis.

The strengths of the current study include the large number of girls participating, representing the paediatric female population attended in primary care. In addition, the study identified incident cases of thyroiditis and provided a new estimation of the incidence that will enable future studies of risk factors and health interventions among girls and adolescent women in Spain. Finally, the case finding algorithm for thyroiditis cases will enable the identification of cases with a known precision over the entire population registered in the database.

\section{Study Limitations}

Some limitations of the current study must be mentioned. First, no PCP or specialists were contacted to confirm the correct recording and diagnoses of thyroiditis. Secondly, although commonly recorded in the medical profiles, thyroid function tests were not straightforward to interpret and thus use as confirmation criteria. For this reason, we relied on written evidence of the diagnosis itself (through a letter to/from a referral or hospital, or free-text comments) to confirm it rather than using the diagnostic criteria. Since that information was less frequently available in the database, we decided to review a small sample size of cases (15\% of the total potential cases identified). We are aware that, even though that sample was randomly selected, its small size could have affected the precision of the predictive values. Finally, the incidence may have been underestimated due to the fact that there was little recorded evidence for case confirmation. For this reason, the incidence including both, 'confirmed' and 'possible' thyroiditis was calculated and reported. The real incidence should be somewhere in between, assuming few false negatives (i.e. cases of thyroiditis not recorded in the clinical profiles).

\section{Conclusion}

This new estimation of the incidence of thyroiditis among girls suggests that cases increased with calendar years and age, and remained stable among girls aged 15-18 years in a Spanish population. Of the thyroiditis cases, more than half were autoimmune, few had other aetiology and for the remaining, the type of thyroiditis was not reported. A delayed diagnosis was suggested in a few patients. Further research about risk factors triggering thyroiditis among paediatric patients, especially if some of these risk factors prove to be preventable, is warranted.

\section{Acknowledgement}

This study is based on data from the Base de datos para la Investigación Farmacoepidemiológica en Atención Primaria (BIFAP) fully financed by the Spanish Agency on Medicines and Medical Devices (AEMPS). The authors would like to acknowledge the excellent collaboration of the primary care paediatricians or general practitioners, and patients taking part in the records and the support of the regional governments. The authors also thank Monica Ríos Martinez (from AEMPS), for her participation in the review of the clinical profiles and Luz María Medrano de Dios (from AEMPS), for her advice concerning thyroiditis definition. 


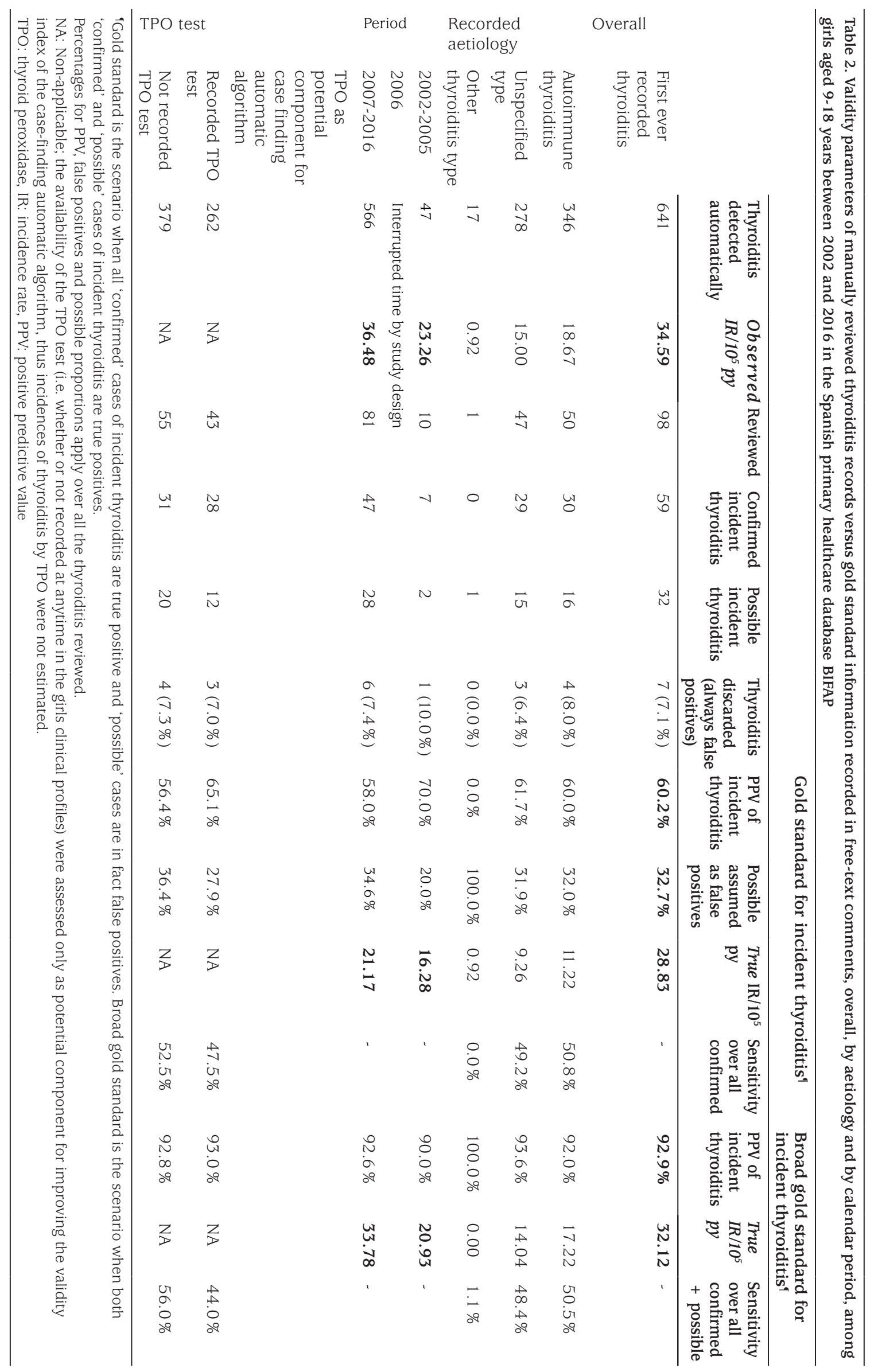




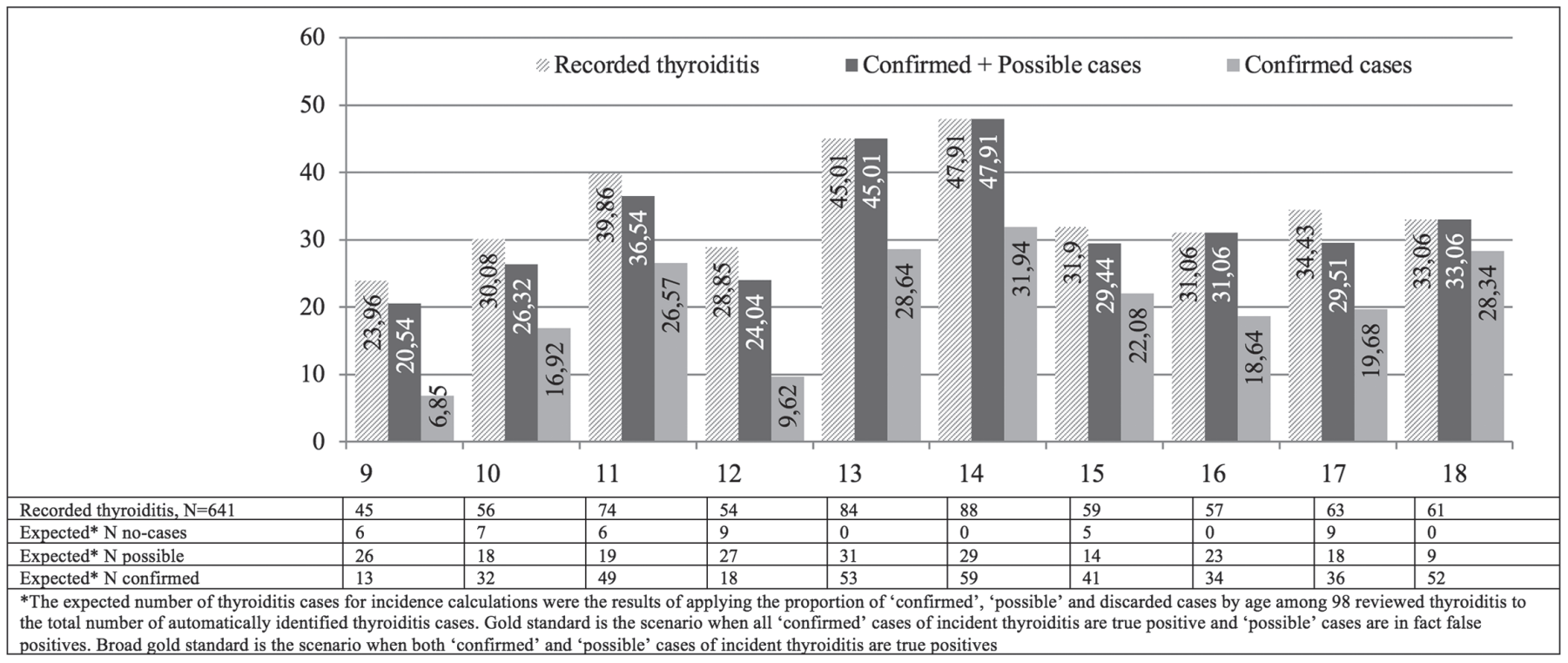

Figure 2. Distribution of recorded and expected thyroiditis cases according to confirmatory information and incidence rate per $10^{5}$ py among girls aged 9-18 years between 2002 and 2016 in Spanish primary healthcare database (BIFAP)

\section{Ethics}

Ethics Committee Approval: The investigators had access to secondary use of only fully anonymized data, and under this condition, no specific ethics review was required according to Spanish law.

Informed Consent: Not applicable according to Spanish law.

Peer-review: Externally peer-reviewed.

\section{Authorship Contributions}

Design: Elisa Martín-Merino, Data Collection or Processing: Elisa Martín-Merino, Belén Castillo Cano, Analysis or Interpretation: Elisa Martín-Merino, Aida Moreno-Juste, Belén Castillo Cano, Mar Martín Pérez, Dolores Montero Corominas, Literature Search: Elisa Martín-Merino, Aida Moreno-Juste, Belén Castillo Cano, Mar Martín Pérez, Writing: Elisa Martín-Merino, Aida Moreno-Juste, Belén Castillo Cano, Mar Martín Pérez, Dolores Montero Corominas.

Financial Disclosure: This study was funded by Instituto de Salud Carlos III through the project "PI17/02300" (Cofunded by European Regional Development Fund and the study protocol was approved by the Scientific Committee of the BIFAP database (Reference BIFAP_01_2016).

\section{References}

1. Diab N, Daya NR, Juraschek SP, Martin SS, McEvoy JW, Schultheiß UT, Köttgen A, Selvin E. Prevalence and Risk Factors of Thyroid Dysfunction in Older Adults in the Community. Sci Rep 2019;9:13156.
2. Sulejmanovic M, Cickusic AJ, Salkic S, Bousbija FM. Annual Incidence of Thyroid Disease in Patients Who First Time Visit Department for Thyroid Diseases in Tuzla Canton. Mater Sociomed 2019;31:130-134.

3. Garmendia Madariaga A, Santos Palacios S, Guillén-Grima F, Galofré JC. The incidence and prevalence of thyroid dysfunction in Europe: a meta-analysis. J Clin Endocrinol Metab 2014;99:923-931. Epub 2014 Jan 1

4. Brown RS. Autoimmune thyroiditis in childhood. J Clin Res Pediatr Endocrinol 2013;5(Suppl 1):45-49. Epub 2012 Nov 15

5. Liliana R Santos, Paulo Fonseca, Rita Cardoso, Paula Soares. Hashimoto's Thyroiditis in Adolescents. Eur Endocrinol 2016;12:85-88.

6. Maciá-Martínez MA, Gil M, Huerta C, Martín-Merino E, Álvarez A, Bryant V, Montero D; BIFAP Team. Base de Datos para la Investigación Farmacoepidemiológica en Atención Primaria (BIFAP): A data resource for pharmacoepidemiology in Spain. Pharmacoepidemiol Drug Saf 2020;29:1236-1245. Epub 2020 Apr 26

7. Porcentaje de población cubierta por el sistema sanitario publico. Encuesta Nacional de Salud. MSSSI/INE. Indicadores clave [Internet]. Sistema Nacional de Salud; 2018 Jun. Available from: http://inclasns. msssi.es/main.html

8. ICPC-2. International classification of primary care. Second Edition. Oxford, Oxford University Press, 1998.

9. International classification of diseases: [9th] ninth revision, basic tabulation list with alphabetic index [Internet]. World Health Organization; 1978 [cited 2017 Sep 26]. Available from: http://www. who.int/iris/handle/10665/39473

10. The Spanish Agency of Medicines and Medical Devices. BIFAP (Base de datos para la Investigación Farmacoepidemiológica en Atención Primaria) [Internet]. [cited 2021 Apr 16]. Available from: http://bifap. aemps.es/

11. Kahaly GJ, Bartalena L, Hegedüs L, Leenhardt L, Poppe K, Pearce SH. 2018 European Thyroid Association Guideline for the Management of Graves' Hyperthyroidism. Eur Thyroid J 201 8;7:167-186. Epub 2018 Jul 25 
12. Bollaerts K, Rekkas A, De Smedt T, Dodd C, Andrews N, Gini R. Disease misclassification in electronic healthcare database studies: Deriving validity indices-A contribution from the ADVANCE project. PloS One 2020;15:e0231333.

13. Chao C, Klein NP, Velicer CM, Sy LS, Slezak JM, Takhar H, Ackerson B, Cheetham TC, Hansen J, Deosaransingh K, Emery M, Liaw KL, Jacobsen SJ. Surveillance of autoimmune conditions following routine use of quadrivalent human papillomavirus vaccine. J Intern Med 2012;271:193-203. Epub 2011 Nov 15

14. Yanai H, Hakoshima M, Katsuyama H. Differences in Clinical and Laboratory Findings Among Graves' Disease, Painless Thyroiditis and Subacute Thyroiditis Patients With Hyperthyroidism. J Endocrinol Metab 2019;9:37-42.

15. Bindra A, Braunstein GD. Thyroiditis. Am Fam Physician 2006;73:17691776.

16. Persani L, Brabant G, Dattani M, Bonomi M, Feldt-Rasmussen U, Fliers E, Gruters A, Maiter D, Schoenmakers N, van Trotsenburg ASP. 2018 European Thyroid Association (ETA) Guidelines on the Diagnosis and Management of Central Hypothyroidism. Eur Thyroid J 2018;7:225237. Epub 2018 Jul 19

17. Willame C, Rosillon D, Zima J, Angelo MG, Stuurman AL, Vroling H, Boggon R, Bunge EM, Pladevall-Vila M, Baril L. Risk of new onset autoimmune disease in 9- to 25-year-old women exposed to human papillomavirus-16/18 AS04-adjuvanted vaccine in the United Kingdom. Hum Vaccines Immunother 2016;12:2862-2871. Epub 2016 Jul 18

18. Léger J, Oliver I, Rodrigue D, Lambert A-S, Coutant R. Graves' disease in children. Ann Endocrinol (Paris) 2018;79:647-655. Epub 2018 Aug 16

19. Wong GW, Cheng PS. Increasing incidence of childhood Graves' disease in Hong Kong: a follow-up study. Clin Endocrinol (Oxf) (Oxf) 2001;54:547-550.
20. Lavard L, Ranløv I, Perrild H, Andersen O, Jacobsen BB. Incidence of juvenile thyrotoxicosis in Denmark, 1982-1988. A nationwide study. Eur J Endocrinol 1994;130:565-568.

21. Williamson S, Greene SA. Incidence of thyrotoxicosis in childhood: a national population based study in the UK and Ireland. Clin Endocrinol (Oxf) 2010;72:358-363. Epub 2009 Sep 21

22. Forssberg M, Arvidsson CG, Engvall J, Lindblad C, Snellman K, Aman J. Increasing incidence of childhood thyrotoxicosis in a population-based area of central Sweden. Acta Paediatr 2004;93:25-29.

23. Rodanaki M, Lodefalk M, Forssell K, Arvidsson CG, Forssberg M, Åman $\mathrm{J}$. The Incidence of Childhood Thyrotoxicosis Is Increasing in Both Girls and Boys in Sweden. Horm Res Paediatr 2019;91:195-202.

24. Simon M, Rigou A, Le Moal J, Zeghnoun A, Le Tertre A, De Crouy-Chanel P, Kaguelidou F, Leger J. Epidemiology of Childhood Hyperthyroidism in France: A Nationwide Population-Based Study. J Clin Endocrinol Metab 2018;103:2980-2987.

25. Dydensborg S, Toftedal P, Biaggi M, Lillevang ST, Hansen DG, Husby S. Increasing prevalence of coeliac disease in Denmark: a linkage study combining national registries. Acta Paediatr 2012;101:179-184. Epub 2011 Jul 22

26. Mayer-Davis EJ, Lawrence JM, Dabelea D, Divers J, Isom S, Dolan L, Imperatore G, Linder B, Marcovina S, Pettitt DJ, Pihoker C, Saydah S, Wagenknecht L; SEARCH for Diabetes in Youth Study. Incidence Trends of Type 1 and Type 2 Diabetes among Youths, 2002-2012. N Engl J Med 2017;376:1419-1429.

27. Havgaard Kjær R, Smedegård Andersen M, Hansen D. Increasing Incidence of Juvenile Thyrotoxicosis in Denmark: A Nationwide Study, 1998-2012. Horm Res Paediatr 2015;84:102-107. Epub 2015 Jun 24

\begin{tabular}{|c|c|c|c|c|c|}
\hline \multirow[t]{2}{*}{ Classification } & \multirow[t]{2}{*}{ Description of classification code ${ }^{¥}$} & \multicolumn{3}{|c|}{ Type of thyroiditis } & \multirow{2}{*}{$\begin{array}{l}\text { Number of cases detected } \\
\text { automatically }\end{array}$} \\
\hline & & Autoimmune & Unspecified & Other & \\
\hline ICPC-BIFAP specific & & & & & 269 \\
\hline T85.1 & BASEDOW, ENF. DE $\S$ & $\mathrm{x}$ & & & 38 \\
\hline T99.16 & HASHIMOTO, ENFERM. DE & $\mathrm{X}$ & & & 21 \\
\hline T99.23 & TIROIDITIS & & $\mathrm{X}$ & & 166 \\
\hline T99.32 & TIROIDITIS DE QUERVAIN & & & $\mathrm{X}$ & \\
\hline T99.39 & TIROIDITIS AUTOINMUNE & $\mathrm{X}$ & & & 42 \\
\hline T99.40 & TIROIDITIS CRONICA AUTOINMUNE & $\mathrm{X}$ & & & 1 \\
\hline T99.41 & TIROIDITIS SUBAGUDA & & & $\mathrm{X}$ & 1 \\
\hline ICD-9-BIFAP specific & & & & & 171 \\
\hline $242.00: 2$ & ENFERMEDAD DE GRAVES BASEDOW & $\mathrm{x}$ & & & 13 \\
\hline $245: 0$ & TIROIDITIS & & $\mathrm{X}$ & & 1 \\
\hline $245.0: 0$ & TIROIDITIS AGUDA & & & $\mathrm{X}$ & 12 \\
\hline $245.1: 0$ & TIROIDITIS SUBAGUDA & & & $\mathrm{X}$ & \\
\hline $245.1: 1$ & TIROIDITIS DE QUERVAIN & & & $\mathrm{X}$ & \\
\hline
\end{tabular}




\begin{tabular}{|c|c|c|c|c|c|}
\hline $245.2: 0$ & TIROIDITIS LINFOCITICA CRONICA & $\mathrm{X}$ & & & \multirow{6}{*}{109} \\
\hline $245.2: 2$ & TIROIDITIS CRONICA AUTOINMUNE & $\mathrm{X}$ & & & \\
\hline $245.2: 5$ & ENFERMEDAD DE HASHIMOTO & $\mathrm{X}$ & & & \\
\hline $245.2: 4$ & TIROIDITIS DE HASHIMOTO & $\mathrm{X}$ & & & \\
\hline $245.2: 1$ & TIROIDITIS CRONICA LINFOCITICA & $\mathrm{X}$ & & & \\
\hline $245.2: 3$ & TIROIDITIS AUTOINMUNE & $\mathrm{X}$ & & & \\
\hline $245.3: 5$ & ESTRUMA FIBROSA & \multicolumn{4}{|c|}{$\mathrm{X}$} \\
\hline $245.3: 1$ & TIROIDITIS INVASIVA & \multicolumn{4}{|c|}{$\mathrm{X}$} \\
\hline $245.3: 2$ & TIROIDITIS LEÑOSA & \multicolumn{4}{|c|}{$x$} \\
\hline $245.3: 4$ & TIROIDITIS DE RIEDEL & \multicolumn{4}{|c|}{$\mathrm{X}$} \\
\hline $245.3: 3$ & TIROIDITIS CRONICA FIBROSA & \multicolumn{4}{|c|}{$X$} \\
\hline $245.3: 0$ & TIROIDITIS FIBROSA CRONICA & \multicolumn{4}{|c|}{$X$} \\
\hline $245.4: 0$ & TIROIDITIS IATROGENICA & \multicolumn{4}{|c|}{$\mathrm{x}$} \\
\hline $245.8: 0$ & $\begin{array}{l}\text { OTRAS TIROIDITIS CRONICAS Y } \\
\text { TIROIDITIS CRONICAS NO ESPECIF }\end{array}$ & \multicolumn{4}{|c|}{$\mathrm{X}$} \\
\hline 245.9:0 & TIROIDITIS NO ESPECIFICADA & & $\mathrm{x}$ & \multirow{2}{*}{\multicolumn{2}{|c|}{35}} \\
\hline $245.9: 1$ & TIROIDITIS & & $\mathrm{X}$ & & \\
\hline
\end{tabular}

\section{String text Searching algorithm (Like, Owa or M \# of separated words)}

$201(80.1 \%$ of them were recorded in Description of ICPC classified as Endocrine/Metabolic and Nutritional, i.e. T-codes)

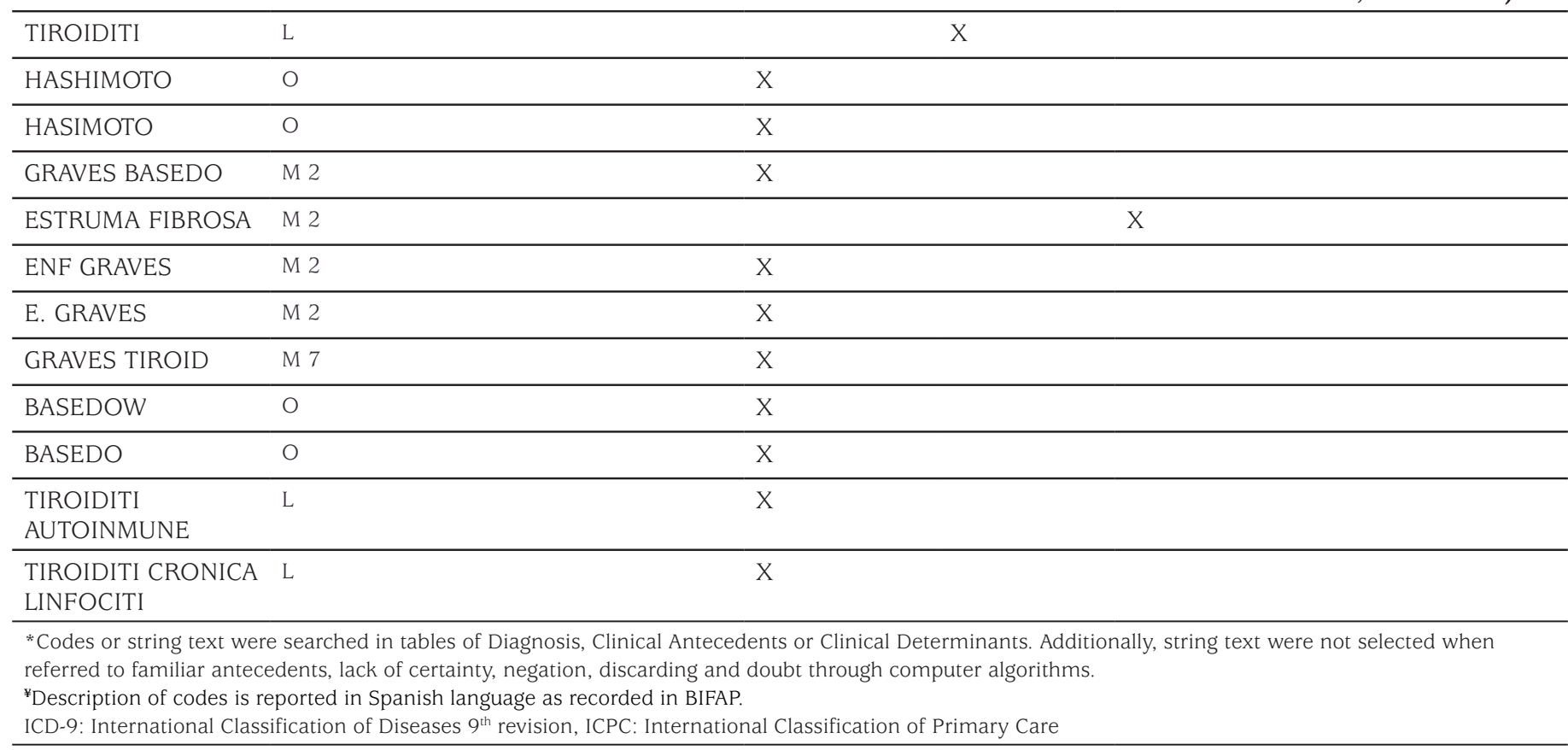

